\title{
Differences in aerodynamic particle size distributions of innovator and generic beclomethasone dipropionate aerosols used with and without a large volume spacer
}

\author{
C J Kenyon, N J Dewsbury, S P Newman
}

\begin{abstract}
Background - The equivalence of generic beclomethasone dipropionate (BDP) formulations with their innovator counterpart must be demonstrated if generic formulations are to be used. This study has examined the aerodynamic particle size distributions of both innovator and generic formulations of BDP and the effect of a large volume spacer (Volumatic) on these distributions.

Methods - Aerosol clouds of three formulations of BDP delivering $250 \mu \mathrm{g}$ per metered dose were characterised using a high precision multistage liquid impinger, and the amount of drug in different particle size bands was determined by spectrophotometric assay.
\end{abstract}

Results - The mean (SD) respirable fractions of Becloforte, Beclazone, and Filair without the spacer $(n=10)$ were $24 \cdot 1$ $(2 \cdot 1) \%, 23 \cdot 1(2 \cdot 7) \%$, and $23 \cdot 0(2 \cdot 1) \%$ respectively; however, the ratio of deposition on stage 4 of the impinger to that on stage 3 was lower for Beclazone and for Filair than for Becloforte, implying a smaller proportion of fine particles for the generic products. When the three products delivered via the Volumatic spacer device were compared, the respirable fraction for Becloforte $(n=10)$ was $25 \cdot 0(4 \cdot 0) \%$, but those of Beclazone $(n=10)$ and Filair $(n=$ 11) were $16.0(1.9) \%$ and $14.6(3.4) \%$. Repeat testing $(n=5)$ at a later date showed higher mean respirable fractions for all three products, but a trend towards the highest respirable fraction for Becloforte, and the same rank order for the other two products.

Conclusions - These in vitro findings suggest that the particle size distributions of the two generic formulations of BDP are not equivalent to that of the innovator product. Some differences in particle size distributions might not have been detected by a twin impinger. Clinical testing would be required to assess the therapeutic equivalence of innovator and generic corticosteroid products used with or without spacer devices.

(Thorax 1995;50:846-850)

Keywords: beclomethasone dipropionate, spacer device, particle size, generic products.
The previous two decades have seen a large expansion in the generic pharmaceutical industry. A generic drug product is intended to be either a substitute for, or interchangeable with, the product of the innovator pharmaceutical company and, in order for this to be the case, equivalence must be demonstrated. Two generic brands of beclomethasone dipropionate (BDP) inhalers are currently available commercially in the UK, in addition to the original innovator product. ${ }^{1}$ High dose inhaled corticosteroids may be associated with both local and systemic side effects, which can be reduced by using large volume spacer devices in conjunction with the standard metered dose inhaler (MDI). ${ }^{23}$ In addition, these spacer devices obviate the need for coordinating actuation with the inhalation manoeuvre. ${ }^{4}$ Current guidelines ${ }^{5}$ recommend the use of a large volume spacer for doses of beclomethasone dipropionate of $800 \mu \mathrm{g}$ per day or more, and for administration of inhaled steroids to children under five years of age. The Volumatic spacer device (Allen and Hanburys) is intended for use with the innovator BDP product, but recently the debate concerning the use of generic MDIs has extended to the use of spacer devices $^{6-9}$ and, in particular, the compatibility of generic brands with an innovator spacer device. The observation of a physical "fit" between the actuator and spacer does not ensure appropriate aerosol characteristics and should not be used to guide the practitioner who wishes to obtain value for money without compromising the therapeutic benefit to the patient.

The penetration of inhaled particles into the airways and their subsequent deposition in the respiratory tract and lungs is controlled in part by the aerodynamic size of the particles. The pharmaceutical industry evaluates the aerodynamic particle size of aerosol systems according to particle inertia which increases with size. Using inertial impingement techniques ${ }^{10-13}$ it is possible to determine the respirable fraction - that is, the percentage of the drug mass which in theory could be delivered to the lungs. The purpose of this in vitro investigation was to characterise the particle size distribution of the innovator corticosteroid beclomethasone dipropionate (Becloforte, Allen and Hanburys) and to compare this with those of two generic formulations of the same drug (Beclazone 250, Baker Norton and Filair 250, 3M Health Care). The characteristics of the three formulations 
when delivered through a Volumatic spacer were also examined.

\section{Methods}

TEST DEVICE

A high precision multistage liquid impinger (HPMLI, Copley Instruments) ${ }^{14}$ was used to fractionate each formulation according to aerodynamic diameter. The device consists of a "throat" (a $90^{\circ}$ bend) and four impaction stages. The aerodynamic diameters of particles trapped in each section of the impinger were approximately as follows: throat, $>25 \mu \mathrm{m}$; stage 1 , $13-25 \mu \mathrm{m}$; stage $2,6.8-13 \mu \mathrm{m}$; stage 3 , $3 \cdot 1-6 \cdot 8 \mu \mathrm{m}$; stage $4,<3 \cdot 1 \mu \mathrm{m}$. Although stage 4 is intended to trap all particles smaller than $3.1 \mu \mathrm{m}$, a Dreschel wash bottle containing methanol was placed downstream of stage 4 to act as a final filter. The same HPMLI was used throughout the investigation, operated at a flow rate of $60 \mathrm{l} / \mathrm{min}$ using a vacuum pump.

\section{TEST PROCEDURES}

High dose corticosteroid inhalers (Becloforte, Beclazone 250, and Filair 250) were used, each inhaler delivering a nominal metered dose of $250 \mu \mathrm{g}$ BDP. The particle size distribution from 10 canisters of each brand was first assessed using the standard MDI actuator alone. Subsequently, particle size following delivery through the Volumatic was measured in three phases, performed approximately three months apart. Phase I was a pilot study that examined the particle size distribution of Becloforte alone, whilst phase II consisted of a full assessment of the three formulations. In both phases the experiment involved measurements on $10 \mathrm{rep}-$ licate canisters, except for phase II measurements on Filair when using the Volumatic where 11 replicates were tested. Phase III again examined all three formulations, each experiment involving five canisters of each product.

Forty metered doses, sufficient to give an adequate ultraviolet absorbance, were fired into the HPMLI in each study. In order to ensure equivalent drug content in each actuation ${ }^{15}$ each MDI was primed using a different actuator prior to use and the first 10 doses were discarded. MDIs were shaken before firing each dose. When testing MDIs alone the vacuum pump was allowed to run continuously as the doses were fired. For the Volumatic, single doses were discharged into the device and these were withdrawn immediately after firing by

Table 1 Mean (SD) percentage distribution of metered dose and total drug recovery for studies without the spacer device

\begin{tabular}{lrrr}
\hline & Becloforte & \multicolumn{1}{c}{ Beclazone } & \multicolumn{1}{c}{ Filair } \\
\hline Actuator & $5 \cdot 5(1 \cdot 3)$ & $4 \cdot 7(0 \cdot 9)$ & $7 \cdot 2(1 \cdot 2)$ \\
Throat & $66 \cdot 3(1 \cdot 9)$ & $65 \cdot 2(2 \cdot 8)$ & $62 \cdot 7(2 \cdot 5)$ \\
Stage 1 & $1 \cdot 4(0 \cdot 4)$ & $2 \cdot 5(0 \cdot 7)$ & $2 \cdot 2(0 \cdot 9)$ \\
Stage 2 & $2 \cdot 6(0 \cdot 6)$ & $4 \cdot 7(0 \cdot 8)$ & $5 \cdot 0(1 \cdot 6)$ \\
Stage 3 & $9 \cdot 6(1 \cdot 6)$ & $11 \cdot 0(1 \cdot 2)$ & $14 \cdot 4(2 \cdot 4)$ \\
Stage 4 & $14 \cdot 4(1 \cdot 9)$ & $12 \cdot 0(2 \cdot 4)$ & $8 \cdot 5(1 \cdot 9)$ \\
Final filter & $0 \cdot 1(0 \cdot 1)$ & $0 \cdot 1(0 \cdot 1)$ & $0 \cdot 1(0 \cdot 0)$ \\
Total drug recovery $(\mu \mathrm{g})$ & $10862(472)$ & $10859(599)$ & $10697(552)$ \\
\hline
\end{tabular}

switching on the vacuum pump. Each spacer device was washed with water and allowed to air dry before use. The Volumatic spacer possesses a one-way valve which allows air to be drawn through the chamber on inspiration but prevents air passing back into the chamber on expiration. In order to simulate the clinical situation and ensure that the inhalation valve was open, the spacers were tilted slightly during the firing and withdrawal of doses. Each component in the system was then thoroughly washed out individually with methanol. New canisters, actuators, and spacers were used for each experiment in each phase of the study and all test materials were supplied by Allen and Hanburys Ltd from randomly selected batches.

The concentration of BDP was determined using an ultraviolet spectrophotometer (Pye Unicam P8735) measuring the absorbance peak at $238 \mathrm{~nm}$. Calibration curves were constructed for the drug to establish a linear working range. The mass of drug in each sample $(\mu \mathrm{g})$ was the product of the concentration of drug $(\mu \mathrm{g} / \mathrm{ml})$ in each sample and the final volume of the solution. In this way the mass of drug on the actuator, the spacer (where applicable), the four impaction stages, and the final filter was determined. The distribution of drug in each zone was expressed as a percentage of the total quantity of drug recovered. The respirable fraction of a formulation was defined as the percentage of drug recovered from stage 3 , stage 4 , and the final filter (particles with an aerodynamic diameter $<6.8 \mu \mathrm{m})$. Two operators were responsible for the experimental procedures and data collection in phases I and II of the study and one of these two individuals performed all the technical procedures for phase III. Quality control of the data analysis was performed by a third investigator throughout all three phases of the study.

\section{DATA ANALYSIS}

The Wilcoxon rank sum test ${ }^{16}$ was used to assess whether the observed differences in particle size distributions between products were statistically significant. A $p$ value of $\leqslant 0.05$ was taken to indicate significance.

\section{Results}

The particle size distributions and total drug recoveries for the three products are shown in table 1 . The mean (SD) respirable fractions of Becloforte, Beclazone, and Filair were 24.1 $(2 \cdot 1) \%, 23 \cdot 1(2 \cdot 7) \%$ and $23 \cdot 0(2 \cdot 1) \%$, respectively (fig 1). However, the Becloforte formulation comprised a higher percentage of particles of $<3.1 \mu \mathrm{m}$ in diameter (recovered from stage 4) with a smaller percentage of particles lying between $3.1 \mu \mathrm{m}$ and $6.8 \mu \mathrm{m}$ in diameter (recovered from stage 3 ). In the Filair formulation the opposite was the case. Beclazone again had a unique particle size distribution; in this case a similar percentage of the dose was deposited on both stages 3 and 4 of the HPMLI. The mean (SD) ratio of the deposition on stage 4 of the impinger to that 


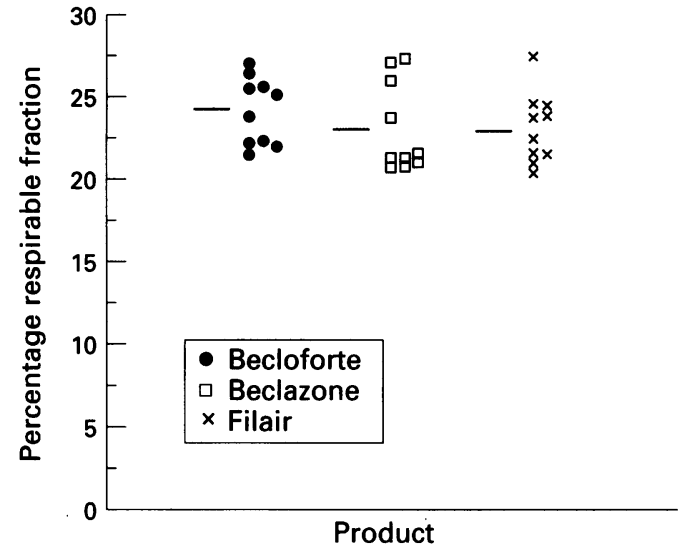

Figure 1 Respirable fractions for each experiment performed with Becloforte, Beclazone, and Filair used without a spacer device. Mean values are indicated by horizontal bars.

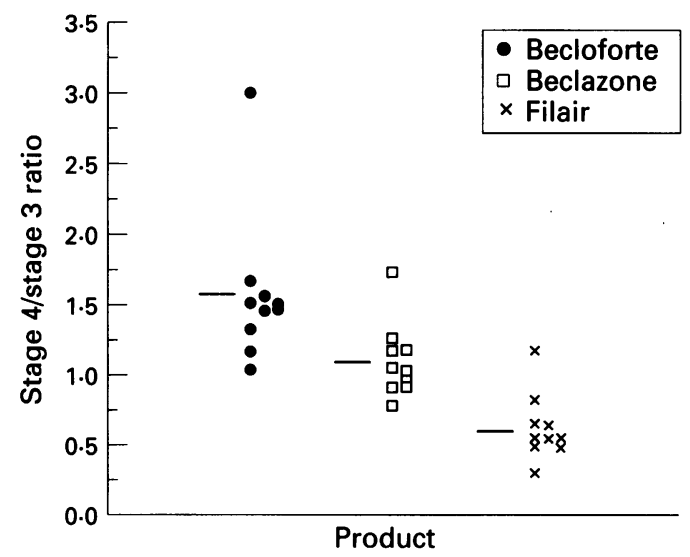

Figure 2 Stage 4/stage 3 deposition ratios for each experiment performed with Becloforte, Beclazone, and Filair used without a spacer device. Mean values are indicated by horizontal bars.

on stage 3 was $1.57(0.54)$ for Becloforte, but only $1 \cdot 10(0 \cdot 26)$ for Beclazone and $0.62(0 \cdot 24)$ for Filair $(p=0.01$ and $p<0.001$, respectively, compared with Becloforte, fig 2).

Particle size distributions and total drug recoveries obtained in each experiment when using the Volumatic spacer are shown in table 2. A pilot investigation performed to examine the delivery of Becloforte when delivered through the Volumatic (phase I) found a respirable fraction of $17 \cdot 8(3.6) \%$, although no comparison was made against the two generic products. However, phase II experiments comparing all three products resulted in respirable

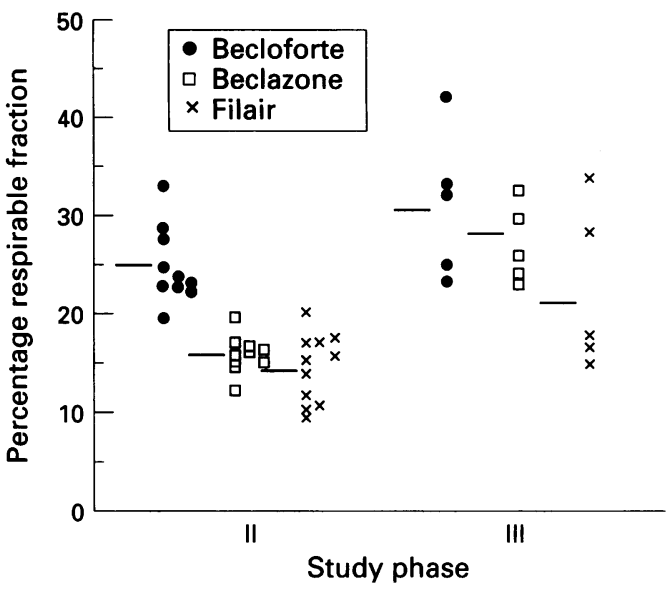

Figure 3 Respirable fractions for each experiment performed with Becloforte, Beclazone, and Filair delivered through a Volumatic spacer device in phases II and III of the study. Mean values are indicated by horizontal bars.

fractions of $25 \cdot 0(4 \cdot 0) \%, 16 \cdot 0(1.9) \%$, and 14.6 (3.4)\% for Becloforte, Beclazone, and Filair, respectively. The mean respirable fraction obtained for Becloforte in phase II of the study was significantly greater $(p<0.01)$ than that obtained for either of the two generic products. Phase III resulted in respirable fractions of $31 \cdot 0(7 \cdot 6 \%), 27 \cdot 0(3 \cdot 9) \%$, and $22 \cdot 2(8 \cdot 3) \%$ for Becloforte, Beclazone, and Filair, respectively. Respirable fractions in phases II and III are shown in fig 3. The significantly higher mean respirable fraction observed for Becloforte in phase II was not repeated during phase III of the study, although only five replicates were performed in this phase of the investigation compared with the 10 or 11 performed for phase II. Fourteen of the 15 impinger runs performed for Becloforte in phases II and III resulted in respirable fractions exceeding $20 \%$ of the metered dose, compared with only three of 16 runs for Filair. The stage 4/stage 3 ratios for the three products for studies with the Volumatic had the highest mean value for Becloforte (phase II: Becloforte $1.60(0.36)$, Beclazone 1.51 (0.16), and Filair $1.39(0 \cdot 26)$; phase III: Becloforte $1 \cdot 79(0 \cdot 29)$, Beclazone $1.64(0.14)$, and Filair $1.37(0.30))$, but this ratio did not differ significantly between the three products.

Mean total drug recoveries (nominal 40 doses of $250 \mu \mathrm{g}$ BDP) ranged from $9795 \mu \mathrm{g}$ to $10861 \mu \mathrm{g}$, suggesting that the inhalation devices and the impinger had been completely washed out prior to drug assay.

Table 2 Mean (SD) percentage distribution of metered dose and total recovery for studies with the Volumatic

\begin{tabular}{|c|c|c|c|c|c|c|c|}
\hline & \multicolumn{3}{|l|}{ Becloforte } & \multicolumn{2}{|l|}{ Beclazone } & \multicolumn{2}{|l|}{ Filair } \\
\hline & Phase I & Phase II & Phase III & Phase II & Phase III & Phase II & Phase III \\
\hline $\begin{array}{l}\text { Actuator } \\
\text { Spacer } \\
\text { Throat } \\
\text { Stage 1 } \\
\text { Stage 2 } \\
\text { Stage 3 } \\
\text { Stage 4 } \\
\text { Final filter }\end{array}$ & $\begin{array}{r}5.0(0.8) \\
74.2(4.3) \\
0.6(0.2) \\
0.7(0.2) \\
1.6(0.2) \\
6.0(1.2) \\
11.8(2.5) \\
0.0(0.0)\end{array}$ & $\begin{array}{r}5.5(0.9) \\
65.4(3.7) \\
1.6(0.5) \\
0.9(0.4) \\
1.7(0.6) \\
9.5(0.7) \\
15.3(3.7) \\
0.2(0.1)\end{array}$ & $\begin{array}{r}4.6(0.6) \\
58.8(8.1) \\
1.3(0.3) \\
1.5(0.2) \\
2.9(0.6) \\
11.3(3.3) \\
19.7(4.7) \\
0.1(0.1)\end{array}$ & $\begin{array}{r}4.8(0.8) \\
74.5(2.1) \\
1.9(0.5) \\
0.8(0.1) \\
2.1(0.4) \\
6.3(0.9) \\
9.5(1.3) \\
0.1(0.1)\end{array}$ & $\begin{array}{r}4.9(1.8) \\
62.0(3.9) \\
1.3(0.2) \\
1.3(0.2) \\
3.6(0.3) \\
10.2(1.8) \\
16.6(2.4) \\
0.2(0.4)\end{array}$ & $\begin{array}{r}5.3(1.4) \\
72.3(2.7) \\
1.3(0.9) \\
4.7(2.0) \\
1.9(0.7) \\
6.2(1.9) \\
8.3(1.9) \\
0.1(0.1)\end{array}$ & $\begin{array}{r}5.6(0.6) \\
62.7(6.2) \\
1.8(0.7) \\
5.2(2 \cdot 7) \\
2.5(0.7) \\
9.7(4 \cdot 6) \\
12.4(4.0) \\
0.0(0.0)\end{array}$ \\
\hline Total drug recovery $(\mu \mathrm{g})$ & $10323(405)$ & $10503(342)$ & $10795(742)$ & $9914(509)$ & $10188(409)$ & $10097(938)$ & $9795(390)$ \\
\hline
\end{tabular}




\section{Discussion}

Our data showed significant differences between the aerodynamic particle size distribution of Becloforte and those of the two generic products, despite the three formulations being intended for use interchangeably. These data suggest that each formulation possesses its own unique delivery characteristics. When used without the Volumatic the reduced ratio of particles in stage 4 of the impinger to those in stage 3 for the two generic products would probably result in a poorer penetration of particles into small peripheral airways. This difference would not have been detected using a twin impinger, which is a device widely employed by the pharmaceutical industry to obtain particle sizing data. ${ }^{113}$ Twin impingers operate by dividing the dose emitted from an MDI into particles which fall within a theoretical "respirable" range and those which do not, and further characterisation of the size distribution of respirable particles is not possible. However, our data have suggested that by measuring only the respirable fraction and not the distribution of particles within the respirable fraction it is not possible to fully characterise the aerosol cloud. We would suggest the use of multistage liquid impingers or cascade impactors such as the Andersen sampler which are already recommended by some regulatory authorities for testing pharmaceutical products.

Our data also showed a significant difference between the aerodynamic particle size distributions of Becloforte and the two generic products when delivered through a large volume spacer. In vitro evaluation of a variety of spacer devices has been performed previously ${ }^{17-19}$ and, in agreement with the present investigation, these studies have found that spacers may either enhance or reduce the respirable fraction. However, the Volumatic is designed for use with Becloforte, and the present study suggests that changes in performance can occur if different aerosol formulations are delivered through the same spacer. Lee ${ }^{20}$ has also examined the delivery through the Volumatic spacer of the same three BDP products as those used in the present study. That study showed mean respirable fractions for $\mathrm{Be}-$ cloforte, Beclazone, and Filair of $26.4 \%$, $23.3 \%$, and $12.9 \%$, respectively, although the data were obtained using the twin impinger and only mean values of respirable fraction were quoted, giving no indication of the scatter of the data. In a recently published letter ${ }^{21}$ the same author claims to have new twin impinger results, suggesting that the respirable fractions of Becloforte and Beclazone are, in fact, similar but the limited data presented were difficult to interpret and a fuller publication is awaited. When all the data from phases II and III of the present study using the Volumatic are pooled, the mean values of respirable fractions for the three products are $27 \cdot 0 \%, 19 \cdot 7 \%$, and $17 \cdot 1 \%$, and these data therefore show the same trend as that reported initially by Lee. ${ }^{20}$ The data from phase I of our study showed a respirable fraction of only $17 \cdot 8 \%$ for Becloforte, but no direct comparison against the other two products was made in that phase of the study.
It was interesting to note that repeat measurements on the same formulation delivered via the Volumatic resulted in different populations of data. The reason for the differences in the data sets is unclear. The total drug recovered from the test system was in good agreement with the expected value throughout the investigation and it was therefore unlikely that these differences were a result of failure to recover all the BDP from the system. In addition, considerable care was taken to ensure that the same HPMLI was used throughout the investigation and the number of operators was kept at a minimum to reduce operator variability. It is possible, however, that interbatch variation between inhalers used in the three phases of the investigation contributed to the differences observed.

Recent evidence suggests that drug delivery from spacer devices is critically affected by static charge. ${ }^{1922}$ The respirable fraction generated through spacer devices has been shown to be significantly altered by simple procedures including lining the spacer with an antistatic spray ${ }^{19}$ and wiping the external surfaces of the device with either an antistatic cloth ${ }^{22}$ or a damp cloth (unpublished observations). In an attempt to minimise differences resulting from static charge in the system each spacer was washed and air dried before use, and was handled in an identical manner during testing. However, the three phases of the study with the Volumatic were performed approximately three months apart, and it is possible that variations in static charge associated with different climatic conditions were responsible, at least in part, for the populations of data observed. For this reason, testing in phase III was performed randomly; one of each of the three products was tested on each day and testing times for each product were rotated throughout the working day.

While we cannot exclude the possibility that the differences observed between the products when delivered via the Volumatic arise from random electrostatic charge effects, the rank order of the mean respirable fractions for the three products was the same in phases II and III, and was the same as that observed by Lee, ${ }^{20}$ suggesting that the differences between the products are real and are not due to experimental variations. The rank order of stage $4 /$ stage 3 ratios in experiments performed without the Volumatic was the same as the rank order of respirable fractions in experiments performed with the Volumatic. Lee and colleagues did suggest that the poor physical fit between the actuator and spacer may have contributed to the low respirable fraction observed for Filair. However, the operators in the present study did not experience problems with the physical fit between the two devices but, nevertheless, observed a low respirable fraction for Filair.

In order to substitute a generic product for the innovator, equivalence of the formulations must be proven and the findings presented here indicate that, when delivering BDP through a standard actuator or through a Volumatic spacer device, the generic products show sig- 
nificant differences in particle size distributions when compared with Becloforte. However, it is not possible to conclude from the present study whether or not such differences between the formulations would have a clinically significant effect. Therapeutic equivalence of the three products can only be assessed by comparative clinical trials which have not been published to date.

This study was supported by a grant from Allen and Hanburys Ltd.

1 British National Formulary No. 27. London: British Medical Association/Pharmaceutical Press, 1994:122.

2 Brown PH, Blundell G, Greening AP, Crompton GK. Do large volume spacer devices reduce the systemic effects of high dose inhaled corticosteroids? Thorax 1990;45:736-9.

3 Toogood JH, Baskerville J, Jennings B, Lefcoe NM, Johansson SA. Use of spacers to facilitate inhaled corticosteroid treatment in asthma. Am Rev Respir Dis 1984;129:723-9.

4 Newman SP. Aerosol generators and delivery systems. Respir Care 1991;36:939-51.

5 British Thoracic Society and others. Guidelines on the management of asthma. Thorax 1993;48(Suppl):S1-24.

6 Bell JH. Volumatic usage. Pharm $\mathcal{f} 1993 ; 251: 511$.

7 Snell N. Volumatic usage. Pharm f 1993;251:544.

8 Bell JH. Volumatic usage. Pharm f 1993;251:652.

9 Snell N. Volumatic usage. Pharm f 1993;251:721.

10 Bell JH, Brown K, Glasby J. Variation in delivery of isoprenaline from various pressurized inhalers. 7 Pharm Pharmacol 1973;25(Suppl):32-6P.
11 Hallworth GW, Westmoreland DG. The twin impinger: a simple device for assessing the delivery of drugs from metered dose pressurized aerosol inhalers. $\mathcal{F}$ Pharm Pharmacol 1987;39:966-72.

12 Hallworth GW. Particle size analysis of therapeutic aerosols In: Morén F, Dolovich MB, Newhouse MT, Newman SP, eds. Aerosols in medicine, 2nd edn. Amsterdam: Elsevier, 1993:351-74

13 Lee MG, Ireland DS, Dwyer PJ, Weir PJ. Comparison of salbutamol inhalers available in the United Kingdom. Int f Pharm Pract 1993;2:172-5.

14 United States Pharmacopiea. Multi-stage liquid impinger. USP, May-June 1993;19:5463.

15 Cyr TD, Graham SJ, Li R, Lovering G. Low first-spray drug content in albuterol metered-dose inhalers. Pharm Res $1991 ; 8: 658-60$.

16 Siegel S, Castellan NJ. Non-parametric statistics for the behavioural sciences. New York: McGraw Hill, 1988

17 Clark AR. In vitro assessment of spacer and reservoir devices. In: Dalby RN, Evans RM, eds. Proceedings of $2 n d$ Respiratory Drug Delivery Conference. Lexington: University of Kentucky, 1991:470-82.

18 Holzner PM, Müller BW. An in vitro evaluation of various spacer devices for metered-dose inhalers using the twin impinger. Int f Pharm 1994;106:69-75.

19 O'Callaghan C, Lynch J, Cant M, Robertson C. Improvement in sodium cromoglycate delivery from a spacer device by use of an antistatic lining, immediate inhalation and avoiding multiple actuations of drug. Thorax 1993; 48:603-6.

20 Lee MG. Generic assessment report 3: beclomethasone inhalers. Mersey Quality Control Service Report, June 1994.

21 Lee MG, Ireland DS, Weir P. Brands interchangeable. Pharm f 1994;253:556.

22 Barry PW, O'Callaghan C. Poor output of salbutamol from a spacer device - the effect of a spacer static charge and multiple actuations. Thorax 1994;49:402P. 